\title{
RESISTÊNCIA INDUZIDA EM TRIGO AO PULGÃO Schizaphis graminum (Rondani, 1852) (HEMIPTERA: APHIDIDAE) POR SILIÍCIO E ACIBENZOLAR-S-METHYL
}

\author{
Induced resistance on wheat to Schizaphis graminum (Rondani,1852) \\ (Hemiptera: Aphididae) by silicon and acibenzolar-s-methyl
}

\author{
Rosane Rodrigues Costa1, Jair Campos Moraes ${ }^{2}$, Cristiana Siqueira Antunes ${ }^{3}$
}

\begin{abstract}
RESUMO
Conduziu-se este trabalho com o objetivo de avaliar o efeito do silício e do acibenzolar-S-methyl na indução de resistência ao pulgão-verde Schizaphis graminum (Rondani, 1852) em trigo. Foram realizados dois experimentos, sendo, no primeiro, as plantas de trigo pulverizadas com ácido silícico e no segundo com silicato de cálcio e/ou acibenzolar-S-methyl. As avaliações foram realizadas através de testes de livre escolha e de tolerância (contagem do número dos pulgões presentes nas plantas e peso seco da parte aérea). Os dados foram submetidos à análise de variância, sendo as médias comparadas pelo teste de Scott-Knott $(\mathrm{P}<0,05)$. Os resultados do experimento com ácido silícico revelaram que o número de pulgões na testemunha foi nove vezes maior que nas plantas que receberam aplicação de ácido silícico, porém não houve diferença significativa no peso seco das plantas entre os tratamentos testados. No segundo experimento, os tratamentos com acibenzolar-S-methyl e posteriormente silício (silicato de cálcio) ou apenas acibenzolar-Smethyl, tiveram menor aceitação pelos pulgões. De maneira geral, a aplicação de silício e/ou acibenzolar-S-methyl aumentou a proteção das plantas de trigo.
\end{abstract}

Termos para indexação: Pulgão-verde, silicato de cálcio, ácido silícico.

\section{ABSTRACT}

The objective of this work was to evaluate the effect of silicon and acibenzolar-S-methyl on the induction of resistance on greenbug Schizaphis graminum (Rondani, 1852) on wheat plants. Two experiments were performed in which in the former wheat plants were sprayed with silicic acid and the other ones' with calcium silicate and/or acibenzolar-S-methyl. The evaluations were by free choice and tolerance tests (counting the number of aphids present on plants and by dry weight of the shoot). The data were submitted to the analysis of variance, the means being compared with by Scott-Knott test $(\mathrm{P}<0.05)$. The results of the experiment with silicic acid showed that the number of aphids on the treatment control was nine times higher compared to sprayed plants with silicic acid. There was no significant difference in the dry weight of the plants among the treatments tested. The plants sprayed with acibenzolar-S-methyl and afterwards with silicon (calcium silicate) or only acibenzolar-S-methyl were less preferred by the aphids. In general, the spray of silicon and/or acibenzolar-S-methyl increases the protection of wheat plants against Schizaphis graminum.

Index terms: Green aphid, calcium silicate, silicic acid.

(Recebido em 22 de março de 2005 e aprovado em 18 de abril de 2006)

\section{INTRODUÇÃO}

O pulgão-verde Schizaphis graminum (Rondani, 1852) (Hemiptera: Aphididae) é um dos principais insetospraga da cultura do trigo. Para o seu controle utilizam-se inseticidas de amplo espectro de ação, porém cada vez menos eficientes, acarretando com isso um maior número de aplicações e dosagens mais altas, ocasionando um maior impacto ao ambiente e ao homem.

O silício é considerado um elemento não essencial, porém pode aumentar o rendimento de algumas espécies cultivadas, promovendo vários processos fisiológicos desejáveis para as plantas (KORNDORFER \& DATNOFF, 1995). A absorção de silício por trigo em condições de campo e sua relação com a evapotranspiração e transpiração foram estudadas por Mayland et al. (1991), que constataram que a absorção apresentou uma correlação linear positiva com a transpiração. A deposição de silício em folhas novas de trigo ocorre predominantemente na epiderme inferior, enquanto que, em folhas velhas, verificase em ambas as epidermes. Resquícios de silício foram detectados em células buliformes, células epidérmicas, parede dos tricomas, esclerênquima epidermal e subepidermal, mesofilo e nos diversos tipos de sistemas vasculares presentes nas folhas (HODSON \& SANGSTER, 1988).

O silício, quando disponível em abundância na solução do solo, pode conferir resistência ao ataque de insetos herbívoros e ao desenvolvimento e penetração de hifas dos fungos nos tecidos vegetais (MARSCHNER, 1995). A proteção conferida às plantas pelo silício pode ser devido ao seu acúmulo e polimerização de silicatados (sílica

\footnotetext{
Engenheira Agrônoma, Doutoranda em Entomologia da Universidade Federal de Lavras/UFLA - Cx. P. 3037 - $37200-000$ - Lavras, MG rosanecosta@bol.com.br

2Professor do Departamento de Entomologia da Universidade Federal de Lavras/ UFLA - Cx. P. 3037 - 37200-000 - Lavras, MG - jcmoraes@ufla.br ${ }^{3}$ Bióloga, Departamento de Entomologia da Universidade Federal de Lavras/UFLA - Cx. P. 3037 - 37200-000 - Lavras, MG.
} 
amorfa) nas células epidêmicas, logo abaixo da cutícula, formando uma barreira mecânica conhecida como "dupla camada silício-cutícula" (YOSHIDA* et al., 1962, citados por SAVANT et al., 1997). A silificação da epiderme impede a penetração de estiletes e a mastigação pelos insetos, devido ao endurecimento da parede das células vegetais (DATNOFF et al., 1991).

Goussain et al. (2002), avaliando o efeito da aplicação de silício em plantas de milho no desenvolvimento biológico da lagarta-do-cartucho Spodoptera frugiperda (J.E. Smith, 1797) (Lepidoptera: Noctuidae), verificaram maior mortalidade e canibalismo de lagartas ao final do segundo instar, quando alimentadas com folhas de plantas de milho tratadas com silicato de sódio. Também foi observado que houve um desgaste acentuado na região incisora das mandíbulas das lagartas, devido, possivelmente, à ação da barreira mecânica proporcionada pela deposição de silício na parede celular das folhas tratadas. Em plântulas de arroz, Kin \& Heinrichs (1982) observaram que poucas ninfas da cigarrinha Sogatella furcifera (Horváth, 1899) (Hemiptera: Delphacidae) transformaram-se em adultos nas plantas tratadas com silício.

Em sorgo, Costa \& Moraes (2002) verificaram que a aplicação de silicato de cálcio induziu resistência ao pulgãoverde $S$. graminum. Para este pulgão em trigo, Basagli et al. (2003) verificaram que a aplicação de silicato de sódio afetou a preferência do pulgão-verde, conferindo as plantas uma moderada resistência. Além disso, os inimigos naturais chaves de pulgões, Chrysoperla externa (Hagen, 1861) (Neuroptera: Chrysopidae) e Aphidius colemani Viereck, 1912 (Hymenoptera: Aphidiidae) não demonstraram alterações em sua biologia quando alimentados com $S$. graminum criado em trigo tratado com silício (MORAES et al., 2004).

Alguns compostos de natureza sintética, como o éster 2-metil benzo-(1,2,3)-tiadiazole-7-carbotióico, de nome químico acibenzolar-S-methyl (ASM), pode levar a ativação de genes que codificam a resistência de plantas (KESSMANN et al., 1994). O ASM é um composto liberado no mercado mundial para a comercialização (FRIEDRICH et al., 1996; LAWTON et al., 1996), não apresentando fitotoxidez em vegetais (GÖRLACH et al., 1996; KUNZ et al., 1997) e facilmente translocado pelos tecidos da planta (FRIEDRICH et al., 1996). A aplicação de ASM em plantas de feijão e abóbora estimulou a atividade das enzimas peroxidases (indutoras da resistência sistêmica adquirida), proporcionando uma maior resistência as plantas tratadas (SIEGRIST et al., 1997; STROBEL et al., 1996; ZHANG et al., 1996). Em tomateiro, Paradela et al. (2001) verificaram a

\footnotetext{
* YOSHIDA, S.; OHNISHI, Y.; KITAGISHI, K. Histochemistry of silicon in rice plant. Soil Science and Plant Nutrition, Tokyo, v. 8, p. 107-111, 1962.
}

eficiência do ASM como indutor de resistência a insetos vetores de fitoviroses.

Dessa forma, o objetivo desse trabalho foi estudar a indução de resistência ao pulgão-verde $S$. graminum por silício e acibenzolar-S-methyl em plantas de trigo.

\section{MATERIAL E MÉTODOS}

\section{Efeito da aplicação de ácido silícico na indução de} resistência ao pulgão-verde $S$. graminum em trigo.

O experimento foi conduzido no Laboratório de Manejo Integrado de Pragas e em casa-de-vegetação do Departamento de Entomologia da Universidade Federal de Lavras. Em vasos com $1 \mathrm{~kg}$ de substrato foram semeadas oito sementes de trigo, cv Embrapa 22, deixando-se após o desbaste, cinco plântulas/vaso. $\mathrm{O}$ delineamento foi o inteiramente ao acaso, com três tratamentos e sete repetições. Foram testados os seguintes tratamentos: 1) uma aplicação de ácido silícico a 0,5\% após 20 dias da emergência; 2) duas aplicações de ácido silícico a 0,5\% após 20 e 30 dias da emergência e 3) testemunha. A solução foi aplicada com pulverizador manual até o escorrimento da calda. A infestação do pulgão-verde ocorreu de maneira natural e as avaliações foram realizadas 10 dias após a última aplicação de silício, pela contagem dos pulgões (ninfas e adultos) presentes nas plantas e determinação do peso seco da parte aérea. Os dados foram submetidos à análise de variância, sendo as médias comparadas pelo teste de Scott \& Knott (1974), a 5\% de significância.

\section{Efeito da aplicação de silicato de cálcio e acibenzolar-S- methyl na indução de resistência ao pulgão-verde $S$. graminum em trigo.}

O experimento foi conduzido no Laboratório de Manejo Integrado de Pragas e em casa-de-vegetação do Departamento de Entomologia da Universidade Federal de Lavras. Em vasos com $2 \mathrm{~kg}$ de substrato foram semeadas oito sementes de trigo, cv Embrapa 22, deixando-se após o desbaste, três plântulas/ vaso. Os tratamentos testados foram: 1) silício + ASM, 2) silício, 3) silício e após 7 dias ASM, 4) ASM, 5) ASM e após 7 dias silício e 6) testemunha. A aplicação dos tratamentos foi iniciada nove dias após a semeadura, via foliar, utilizando silicato de cálcio $1 \%$ e ASM a $0,005 \%$. Adotou-se o delineamento inteiramente ao acaso, com oito repetições.

Aos 23 dias da semeadura, retirou-se uma planta de cada vaso para a montagem do teste de livre escolha, infestando-se as duas plantas restantes/vaso com três pulgões adultos, sendo, posteriormente, cada vaso protegido por gaiola de estrutura metálica de $50 \times 50 \times 80 \mathrm{~cm}$, revestida com tecido tipo organza. Colheram-se as plantas aos nove dias da infestação para contagem das ninfas e adultos de pulgões e determinação do peso seco da parte aérea. 
As plantas, anteriormente destacadas dos vasos, foram levadas para o Laboratório de Manejo Integrado de Pragas onde foi realizada a avaliação da preferência ou teste de livre escolha. Seções foliares das plantas, de cada tratamento, foram colocadas em placas de Petri e, em seguida, 20 pulgões no centro da arena formada. As avaliações foram realizadas após 48 horas pela contagem de pulgões presentes em cada seção foliar. Os dados foram submetidos à análise de variância, e transformados para $\sqrt{\mathrm{x}+0,5}$ exceto o peso seco da parte aérea das plantas e as médias comparadas pelo teste de Scott \& Knott (1974), a $5 \%$ de significância.

\section{RESULTADOS E DISCUSSÃO}

Não houve diferença significativa no peso seco entre os tratamentos testados. Contudo, o número de pulgões na testemunha foi nove vezes maior que nas plantas que receberam aplicação de ácido silícico (Tabela 1). Resultados semelhantes foram obtidos por Costa \& Moraes (2002), que aplicando silicato de sódio por aspersão no coleto das plântulas de sorgo, verificaram que o silício proporcionou moderada resistência ao pulgão-verde.

No segundo experimento, no teste de livre escolha, as seções de folhas de plantas tratadas com ASM e posteriormente silício (silicato de cálcio) e apenas ASM foram menos colonizados pelo pulgão-verde (Tabela 2). Moraes et al. (2004) também verificaram que a aplicação de silício aumentou o grau de resistência das plantas de trigo diminuindo a preferência do pulgão-verde em relação à testemunha.

Pode-se verificar (Tabela 3) que não houve diferenças significativas no peso seco da parte área, mesmo quando a avaliação foi realizada no inicio de desenvolvimento das plantas. No teste sem chance de escolha, o número de adultos e de ninfas do pulgão-verde foi menor nos tratamentos que receberam Silício + ASM e ASM. O número de adultos também foi afetado negativamente pela aplicação de Silício e após sete dias ASM (Tabela 3). Estes resultados concordam com os de Correa (2004), que aplicando silicato de cálcio e acibenzolar-Smethyl em pepino para indução de resistência à mosca-branca, conclui que as plantas que receberam estes compostos induziram mecanismos de não-preferência para oviposição de Bemisia tabaci (Gennadius,1889) biótipo B e causaram alta mortalidade de ninfas. De maneira semelhante, Paradela et al. (2001) verificaram a eficiência do ASM como indutor de resistência a insetos vetores de fitoviroses em tomateiro.

A aplicação de silício e/ou de acibenzolar-S-methyl, pode constituir em mais uma tática alternativa de manejo de pulgão-verde na triticultura.

TABELA 1 - Número médio de pulgões Schizaphis graminum em folhas de trigo tratadas com ácido silícico e peso seco da parte aérea das plantas.

\begin{tabular}{lcc}
\hline \multicolumn{1}{c}{ Tratamento } & No Médio de Pulgões* & $\begin{array}{c}\text { Peso seco parte aérea } \\
\text { (g)*/planta }\end{array}$ \\
\hline Uma aplicação de ácido silícico a 0,5\% & $45,6 \mathrm{a}$ & $2,14 \mathrm{a}$ \\
Ácido silícico $(0,5 \%)$ 2 aplicações & $43,7 \mathrm{a}$ & $2,22 \mathrm{a}$ \\
Testemunha & $408,3 \mathrm{~b}$ & $2,38 \mathrm{a}$ \\
\hline $\mathrm{CV}(\%)$ & 60,98 & 29,53 \\
\hline
\end{tabular}

* Médias seguidas pela mesma letra na coluna não diferem entre si pelo teste de Scott-Knott $(\mathrm{P}<0,05)$.

TABELA 2 - Número médio de pulgões Schizaphis graminum em folhas de trigo tratadas com silício e/ou ASM, em teste de livre escolha, após 48 horas da infestação.

\begin{tabular}{lc}
\hline \multicolumn{1}{c}{ Tratamento } & Pulgões* \\
\hline Silício + ASM & $4,75 \mathrm{a}$ \\
Silício & $4,50 \mathrm{a}$ \\
Silício e após sete dias ASM & $4,70 \mathrm{a}$ \\
ASM & $2,25 \mathrm{~b}$ \\
ASM e após sete dias Silício & $1,75 \mathrm{~b}$ \\
Testemunha & $3,87 \mathrm{a}$ \\
\hline $\mathrm{CV}(\%)$ & 28,26 \\
\hline
\end{tabular}

* Médias seguidas pela mesma letra na coluna não diferem entre si pelo teste de Scott-Knott $(\mathrm{P}<0,05)$. 
TABELA 3 - Número médio de pulgões adultos e de ninfas de Schizaphis graminum em folhas de trigo tratadas com silício e/ou ASM, em teste de preferência sem chance de escolha, e peso seco da parte aérea das plantas.

\begin{tabular}{lccc}
\hline \multicolumn{1}{c}{ Tratamento } & Adultos* $^{*}$ & Ninfas* $^{*}$ & ${\text { Peso seco parte aérea }(\mathbf{g})^{*}}^{\text {Silício + ASM }}$ \\
Silício & $8,62 \mathrm{~b}$ & $11,12 \mathrm{~b}$ & $0,20 \mathrm{a}$ \\
Silício e após sete dias ASM & $13,62 \mathrm{a}$ & $11,50 \mathrm{a}$ & $0,24 \mathrm{a}$ \\
ASM & $8,25 \mathrm{~b}$ & $37,12 \mathrm{a}$ & $0,32 \mathrm{a}$ \\
ASM e após sete dias Silício & $5,75 \mathrm{~b}$ & $21,25 \mathrm{~b}$ & $0,26 \mathrm{a}$ \\
Testemunha & $14,25 \mathrm{a}$ & $21,25 \mathrm{a}$ & $0,27 \mathrm{a}$ \\
CV $(\%)$ & $15,50 \mathrm{a}$ & $24,5 \mathrm{a}$ & $0,29 \mathrm{a}$ \\
\hline
\end{tabular}

* Médias seguidas pela mesma letra na coluna não diferem entre si pelo teste de Scott-Knott $(\mathrm{P}<0,05)$.

\section{CONCLUSÃO}

A aplicação de silício e/ou de acibenzolar-S-methyl permite proteção em plantas de trigo ao pulgão-verde.

\section{AGRADECIMENTOS}

À FAPEMIG e à CAPES pelo apoio financeiro e concessão de bolsa, respectivamente.

\section{REFERÊNCIAS BIBLIOGRÁFICAS}

BASAGLI, M. A. B.; MORAES, J. C.; CARVALHO, G. A.; ECOLE, C. C.; GONÇALVES-GERVÁSIO, R. C. R. Effect of sodium silicate on the resistance of wheat plants to greenaphids Schizaphis graminum (Rond.) (Hemiptera: Aphididae). Neotropical Entomology, Londrina, v. 32, n. 3, p. 659-663, July/Sept. 2003.

CORREA, R. S. B. Silício e acibenzolar-S-methyl como indutores de resistência à mosca-branca Bemisia argentifolii Bellows \& Perring, 1994 (Hemiptera: Aleyrodidae) em plantas de pepino. 2004. 59 p. Dissertação (Mestrado em Entomologia) - Universidade Federal de Lavras, Lavras, 2004.

COSTA, R. R.; MORAES, J. C. Resistência induzida em sorgo por silicato de sódio e infestação inicial pelo pulgão-verde Schyzaphis graminum. Revista Ecossistema, Espírito Santo do Pinhal, v. 27, n. 1/2, p. $37-$ 39, 2002.

DATNOFF, L. E.; RAID, R. N.; SNYDER, G. H.; JONES, D. B. Effect of calcium silicate on blast and brown spot intensities and yields of rice. Plant Disease, Saint Paul, v. 75, n. 7, p. 729-732, July 1991.
FRIEDRICH, L.; LAWTON, K.; RUESS, W.; MASNER, P.; SPECKER, N.; RELLA, M. G.; MEIER, B.; DINCHER, S.; STAUB, T.; UKNES, S.; MÉTRAUX, J.; KESSMANN, H.; RYALS, J. A benzothiadiazole derivate induces systemic acquired resistance in tobacco. The Plant Journal, Oxford, v. 10, n. 1, p. 61-70, Jan. 1996.

GÖRLACH, J.; VOLRATH, S.; KNAUF-BEITER, G.; HENGY, G.; BECKHOVE, U.; KOGEL, K.; OOSTENDORP, M.; STAUB, T.; WARD, E.; KESSMANN, H.; RYALS, J. Benzothiadiazole, a novel class of inducers of systemic acquired resistence, activates gene expression and disease resistence in wheat. The Plant Cell, Rockville, v. 8, n. 4, p. 629-643, Apr. 1996.

GOUSSAIN, M. M.; MORAES, J. C.; CARVALHO, J. C.; NOGUEIRA, N. L. Efeito da aplicação de silício em plantas de milho no desenvolvimento biológico de lagarta-docartucho Spodoptera frugiperda (J.E. Smith) (Lepidoptera: Noctuidae). Neotropical Entomology, Londrina, v. 31, n. 2, p. 305-310, May/June 2002.

HODSON, M. J.; SANGSTER, A. G. Observations on the distribuition of mineral elements in the leaf of wheat (Triticum aestivum L.), with particular reference to silicon. Annuals of Botany, London, v. 62, n. 5, p. 463-471, Nov. 1988.

KESSMANN, H.; STAUB, T.; HOFFMANN, C.; MAETZKE, T.; HERZOG, J.; WARD, E.; UKNES, S.; RYALS, J. Induction of systemic acquired disease resistance in plants by chemicals. Annual Review of Phytopathology, Palo Alto, v. 32, p. 439-459, 1994. 
KIN, H. S.; HEINRICHS, E. A. Effects of silica level on whitebacked planthopper. International Rice Research Newsletter, Manial, v. 7, n. 4, p. 17, 1982.

KORNDÖRFER, G. A.; DATNOFF, L. E. Adubação com silício: uma alternativa no controle de doenças de canade-açúcar e do arroz. Informações Agronômicas, Piracicaba, n. 70, p. 1-5, jun. 1995.

KUNZ, W.; SCHURTER, R.; MAETZKE, T. The chemistry of benzothiadiazole plant activators. Pesticide Science, New York, v. 50, n. 4, p. 275-282, Aug. 1997.

LAWTON, K. A.; FRIEDRICH, L.; HUNT, M.; WEYMANN, K.; DELANEY, T.; KESSMANN, H.; STAUB, T.; RYALS, J. Benzothiadiazole induces disease resistance in Arabidopsis by activation of the systemic acquired resistance signal transduction pathway. The Plant Journal, Oxford, v. 10, n. 1, p. 71-82, Jan. 1996.

MARSCHNER, H. Mineral nutrition of higher plants. 2. ed. London: Academic, 1995. 889 p.

MAYLAND, H. F.; WRIGHT, J. L.; SOJKA, R. E. Silicon accumulation and water upiake by wheat. Plant Soil, Dordrecht, v. 137, n. 2, p. 191-199, Nov. 1991.

MORAES, J. C.; GOUSSAIN, M. M.; BASAGLI, M. A. B.; CARVALHO, G. A.; ECOLE, C. C.; SAMPAIO, M. V. Silicon influence on the tritrophic interaction: wheat plants, the Gressnbug Schizaphis graminum (Rondani) (Hemiptera: Aphididae), and its natural enemies, Chrysoperla externa (Hagen) (Neuroptera: Chrysopidae) and Aphidius colemani Viereck (Hymenoptera: Aphidiidae). Neotrotropical Entomology, Londrina, v. 33, n. 5, p. 619-624, 2004.
PARADELA, A. L.; SCACHETTI, A. P.; MUNHOZ, R.; BORIM JÚNIOR, N.; CLAFIORI, M. H.; GALLI, M. A. Eficiência de bion (acibenzolar-S-methyl) como indutor de resistência para o complexo bacteriano (Xanthomonas vesicatoria; Pseudomonas syringae pv. Tomato e Clavibacter michiganense subsp. michiganense) e insetos vetores de fitoviroses na cultura do tomate (Licopersicon esculentum L.). Ecossistema, Espírito Santo do Pinhal, v. 26, n. 1, p. 17-23, jan./jul. 2001.

SAVANT, N. K.; DATNOFF, L. E.; SNYDER, G. H. Depletion of plant available silicon in soils: a possible cause of declining rice yields. Communications Soil Science in Plant Analysis, New York, v. 28, n. 13/14, p. 1245-1252, 1997.

SIEGRIST, L.; GLENEWINKEL, D.; KOLLE, C.; SCHMIDTKE, M. Chemically induced resistance in green bean against bacterial and fungal pathogens. Journal of Plant Disease and Protection, Stuttgart, v. 104, n. 6, p. 599610, Dec. 1997.

SCOTT, A. J.; KNOTT, M. A. A cluster analysis method for grouping means in the analysis of variance. Biometrics, Washington, v. 30, p. 507-512, 1974.

STROBEL, N. E.; GOPALAN, S.; KUC, J. A.; HE, S. Y. Induction of systemic acquired reistance in cucumber by Pseudomonas syringae pv. syringae 61 HrpZPss protein. Plant Journal, Oxford, v. 9, n. 4, p. 431-439, Apr. 1996.

ZHANG, W.; DICK, W. A.; HOITINK, H. A. Compostinduce systemic acquired resistance in cucumber to Pythium root rot and Anthracnose. Phytopathology, Saint Paul, v. 86, n. 10, p. 1066-1070, Oct. 1996. 